\title{
Synthesis, and Characterization, and Evaluation of Cellular Effects of the FOL-PEG-g-PEI-GAL Nanoparticles as a Potential Non-Viral Vector for Gene Delivery
}

\author{
S. Ghiamkazemi, ${ }^{1,2,3}$ A. Amanzadeh, ${ }^{4}$ R. Dinarvand, ${ }^{1,2}$ M. Rafiee-Tehrani, ${ }^{1,2}$ and M. Amini ${ }^{3,5}$ \\ ${ }^{1}$ Pharmaceutical Sciences Research Center, Tehran University of Medical Sciences, Tehran 14174, Iran \\ ${ }^{2}$ Department of Pharmaceutics, Faculty of Pharmacy, Tehran University of Medical Science, Tehran, Iran \\ ${ }^{3}$ Department of Medicinal Chemistry, Faculty of Pharmacy, Tehran University of Medical Sciences, Tehran, Iran \\ ${ }^{4}$ National Cell Bank of Iran (NCBI), Pasteur Institute of Iran, Tehran, Iran \\ ${ }^{5}$ Drug Design and Development Research Center, Tehran University of Medical Sciences, Tehran, Iran
}

Correspondence should be addressed to M. Amini, moamini@sina.tums.ac.ir

Received 16 February 2010; Revised 15 June 2010; Accepted 17 June 2010

Academic Editor: Maryam Tabrizian

Copyright ( $\odot 2010$ S. Ghiamkazemi et al. This is an open access article distributed under the Creative Commons Attribution License, which permits unrestricted use, distribution, and reproduction in any medium, provided the original work is properly cited.

In this manuscript, we synthesized the potential non viral vector for gene delivery with proper transfection efficiency and low cytotoxicity. Polyethylenimine (PEI) is a well-known cationic polymer which has high positive surface charge for condensing plasmid DNA. However; it is highly cytotoxic in many cell lines because of the high surface charge, non-biodegradability and nonbiocompatibility. To enhance PEI biodegradability, the graft copolymer "PEG-g-PEI" was synthesized. To target cancer liver cells, two targeting ligands folic acid and galactose (lactobionic acid) which are over expressed on human hepatocyte carcinoma were attached to graft copolymer and "FOL-PEG-g-PEI-GAL" copolymer was synthesized. Composition of this grafted copolymer was characterized using ${ }^{1} \mathrm{H}-\mathrm{NMR}$ and FTIR spectra. The molecular weight and zeta potential of this copolymer was compared to PEI. The particle size and zeta potential of FOL-PEG-g-PEI-GAL/DNA complexes at various N/P ratio were measured using dynamic light scattering (DLS). Cytotoxicity of the copolymer was also studied in cultured HepG2 human hepatoblastoma cell line. The FOL-PEG-g-PEI-GAL/DNA complexes at various N/P ratios exhibited no cytotoxicity in HepG2 cell line compared to PEI 25K as a control. The novel copolymer showed enhanced biodegradability in physiological conditions in compared with PEI and targeted cultured HepG2 cells. More importantly, significant transfection efficiency was exhibited in cancer liver cells. Together, our results showed that "FOL-PEG-g-PEI-GAL" nanoparticals could be considered as a useful non-viral vector for targeted gene delivery.

\section{Introduction}

In recent years, there has been an enormous interest ex vivo and in vivo gene therapy approaches, which necessitate the formulation of DNA into vectors for targeting a specific population of cell either locally or systemically. The gene delivery to target cells can be achieved by either viral or nonviral methods [1-3]. Viral gene delivery has been studied for years, but more recently, the broad use of viral system is affected by the limited size of genetic material delivered, severe safety risks, and no targeting interaction to certain cells [2-4]. Viral vectors are also expensive to manufacture and have difficulties in bypassing the immune defense mechanism $[2,3]$.
Therefore, non-viral gene delivery has become a promising alternative since the vectors could be synthesized with high purity and quality degree and with less immunogenic response than the viral vectors [3-5]. An ideal vector which was used in gene therapy needs to be inert while in circulation and release its payload at the target site resulting in an efficient transfection of the cells. The used vector should have sufficiently small size lower than $300 \mathrm{~nm}$ to efficiently enter target cells. If the particle size would be larger than $300 \mathrm{~nm}$, the vector cannot enter the cells, and if the particle size would be very small, the aggregation in blood circulation can be happened $[4$, 5]. 
Cationic lipids and biodegradable polymers have been synthesized to condense DNA and promote efficient intracellular delivery $[4,5]$. Among the cationic polymers, polyethylenimine (PEI) has emerged to be one of the most popular reagents for transfection of cells in culture. However, its application in vivo has been limited in reason of multiple cationic charges on its surface and therefore including the difficulties targeting therapeutic sites, high zeta-potential, and nonbiodegradability, non-biocompatibility properties in serum media $[4,5]$.

Low stability and short circulation time in blood stream are still challenges. Therefore, efficient and less toxic and biodegradable polycation gene carriers are highly desirable for therapeutically non-viral gene delivery.

For this proper goal, in this study, polyethylenimine was modified with polyethylene glycol to enhance biodegradability in serum [6]. To target cancer liver cells, pegylated PEI was conjugated with two targeting ligands (galactose and folic acid).

The asialoglycoprotein receptor (ASGP-R) is known to be present only on hepatocytes at a high density of 500,000 receptors per cell [7-9] and gene delivery system via the (AGSP-R) is one of the effective gene delivery systems into the liver in vivo [9-12]. This hepatocyte-specific receptor recognizes and interacts with galactose (lactobionic acid) ligand on the PEG-g-PEI-GAL copolymer resulting in the uptake of the copolymer by the hepatocytes.

Folate has been popularly used as a targeting ligand for large fraction of human tumors $[6-8,10]$. It has been known for nearly a decade that simple covalent attachment of folic acid to any macromolecule produces a conjugate that can be internalized into FR-bearing cells in an identical fashion to that of free folic acid $[6,8]$. In summary, a new folate conjugated copolymer is capable of modulating its specific cell uptake and improving the level of cell transfection in folate expressing cells $[6-8,10]$.

In the present study, a novel non-viral vector for gene delivery was synthesized via reaction of graft copolymer "PEG-g-PEI" with folic acid and galactose (lactobionic acid). Decreasing the cationic surface charge of polyethylenimine could diminish the cytotoxicity. Furthermore, this new copolymer has been targeted for cancer liver cells (HepG2), and it seems that this obtained nanoparticle may be suitable for targeted gene delivery and drug delivery purposes.

\section{Materials and Methods}

Branched Polyethylenimine 25 KD (PDI: 1.2 and purity $97 \%$ ) was supplied from Sigma-Aldrich (St. Louis, MO, USA) and used without further purification. Poly (ethylene) glycol (COOH-PEG-NH2, MW $3400 \mathrm{Da}$ ) was obtained from Nektar (Huntsville, Al). Folic acid and N-Hydroxy succinimide (NHS) and N-(3-Dimethylaminopropyl)-N-ethyl carbodiimide hydrochloride (EDC) and lactobionic acid were obtained from Sigma (St. Louis, Mo, USA).

Dichloromethane and methanol were purchased from Merck (Darmsthdat, Germany).
The reporter plasmid expressing green fluorescent protein (pAAV-EGFP) was purchased from Promega (Madison, WI, USA). The Human hepatocyte carcinoma (HepG2 cells) was obtained from NCBI C158 (National Cell Bank of Iran). Dulbecco's Modified Eagle's Medium [DMEM] was supplemented with $10 \%$ fetal calf serum (FCS-Seromed, Germany) and L-glutamine (Gibco-BRL, USA). The other materials used were of pharmaceutical or analytical grade and used as received.

\section{Instrumentation}

(i) The ${ }^{1} \mathrm{H}-\mathrm{NMR}$ spectrums were obtained in D2O using $500 \mathrm{MHz}$ spectrometer (Bruker Ac 500, Germany).

(ii) The FTIR spectrophotometer (Nicolet 550 A, USA) was used to record spectrums.

(iii) The Molecular weights of lyophilized polymers were measured by Gel permeation chromatography (GPC) (Krauna, Germany).

(iv) The particle sizes and surface charges of novel copolymer complexes with plasmid DNA (prepared polyplexes) were measured at room temperature using an electrophoretic light scattering spectrophotometer (Zetasizer 3000 HAS, Malvern instruments Ltd, Uk) at scattering angles of $90^{\circ}$ and $20^{\circ}$, respectively.

(v) The Elisa plate reader (Stat Fax 2100-USA) was used to read the results of MTT assay.

(vi) The transfection efficiency was evaluated by scoring the percentage of fluorescent cells using an FACS Aria System from Becton-Dickson (San Joes, CA, USA).

3.1. Preparation of Pegylated Polyethylenimine (PEG-g-PEI). Initially, one $\mathrm{g}(0.3 \mathrm{mmole})$ of $\mathrm{COOH}-\mathrm{PEG}-\mathrm{NH}_{2}$ was dissolved in $50 \mathrm{~mL}$ of dichloromethane. NHS and EDC were added with 3-fold molar excess based on COOH-PEG-NH .

The mixture was stirred for $3 \mathrm{~h}$ at room temperature. To the magnetically stirred solution; five $\mathrm{g}(0.2 \mathrm{mmole})$ of PEI and $50 \mathrm{~mL}$ of dichloromethane were added. The mixture was refluxed for $48 \mathrm{~h}$ at $48^{\circ} \mathrm{C}$, and the solvent was removed under reduced pressure.

$\mathrm{NH}_{2}$-PEG-g-PEI copolymer was yielded as white gellike. One hundred $\mathrm{mL}$ of water was added to the crude and filtered. The filtered water was removed under reduced pressure.

The purified precipitation was dried at room temperature. The ${ }^{1} \mathrm{H}-\mathrm{NMR}$ spectrum was obtained from precipitate, and the degree of substitution of PEG on PEI was determined by ${ }^{1} \mathrm{H}$-NMR spectrometry. The FTIR spectrophotometer was used to record spectrum.

3.2. Preparation of Folate-PEG-g-PEI. The PEI-g-PEG-FOL conjugate was synthesized with slight modification. Initially, $250 \mathrm{mg}$ ( $0.566 \mathrm{mmole})$ of folic acid was added to $60 \mathrm{~mL}$ methanol and magnetically stirred for $1 \mathrm{~h}$ at $100^{\circ} \mathrm{C}$ until folic acid was dissolved completely. EDC was added with 4-fold molar excess, based on folic acid, and the mixture was stirred for $4 \mathrm{~h}$ at room temperature. 
$250 \mathrm{mg}$ of obtained graft copolymer, PEG-g-PEI, in previous stage was dissolved in $20 \mathrm{~mL}$ of methanol and added to the mixture of activated folate in methanol.

The mixture was stirred for $72 \mathrm{~h}$ at room temperature. The new copolymer was dialyzed with dialyzed filtration (MWCO 12000) against deionized water to remove unreacted substrates and dried to obtain brown gel-like precipitate with high water solubility. The H-NMR spectrum was obtained in D2O. The stoichiometric molar ratio of conjugation between folic acid and PEG-g-PEI was calculated.

3.3. Preparation of Folate-PEG-g-PEI-Galactose. To $128 \mathrm{mg}$ (0.34 mmole) of lactobionic acid (galactose) were added $10 \mathrm{~mL}$ of water, and EDC/NHS were added with a 4 -fold molar excess based on lactobionic acid, and the mixture was stirred for $5 \mathrm{~h}$ at room temperature.

$128 \mathrm{mg}$ of synthesized copolymer in previous stage was dissolved in $5 \mathrm{~mL}$ water well, and this solution was added to the mixture of activated galactose solution and stirred for $48 \mathrm{~h}$ at room temperature. The product was dialyzed (MWCO 12000) against deionized water and then freeze dried. The ${ }^{1} \mathrm{H}-\mathrm{NMR}$ spectrum was obtained in $\mathrm{D} 2 \mathrm{O}$, and the degree of substitution of lactobionic acid in conjugated copolymer was determined.

3.4. Characterization and Evaluation of FOL-PEG-g-PEI-GAL Copolymer. The composition of the prepared FOL-PEG-gPEI-GAL copolymer was estimated by measuring ${ }^{1} \mathrm{H}-\mathrm{NMR}$. The zeta potential of the copolymers was compared with branched polyethylenimine $25 \mathrm{KD}$ using Zetasizer.

The molecular weight of the copolymers was measured using gel permeation chromatography with multiangle laser scattering with $690 \mathrm{~nm}$ laser wave lengths.

3.5. Degradation of Copolymers. Copolymer degradation was estimated by measurement of molecular weight of synthesized copolymer.

One $\mathrm{g}$ of each copolymer was dissolved in $2 \mathrm{~mL}$ of phosphate buffer saline (PBS) and incubated at $37^{\circ} \mathrm{C}$ with shaking at $100 \mathrm{rpm}$ for specified times [6].

After incubation, solutions of copolymers were lyophilized, and the molecular weights of lyophilized samples were measured by GPC instrument and the results were compared with branched PEI as a control [6].

3.6. Preparation of Plasmid. The reporter plasmid expressing green fluorescent protein (pAAV-EGFP) plasmid was used in this study. Plasmid DNA was amplified in Escherichia coli and purified according to the manufacturer's instructions (QIAGEN, CA, USA). The quantity and quality of the purified plasmid DNA were assessed by measuring its optical density at 260 and $280 \mathrm{~nm}$ and by electrophoresis in $1 \%$ agarose gel. The purified plasmid DNA was kept in aliquots at a concentration of $1 \mu \mathrm{g} / \mu \mathrm{L}$.

3.7. Preparation and Characterization of FOL-PEG-g-PEIGAL/DNA Nanoparticles. All FOL-PEG-g-PEI-GAL/DNA complexes were freshly prepared before use.
FOL-PEG-g-PEI-GAL/DNA complexes were prepared by combining equal volumes of a DNA solution and copolymer solution, gently vortexing the solution, and the nanoparticles were incubated at room temperature for $30 \mathrm{~min}$.

Characterization of FOL-PEG-g-PEI-GAL/DNA complexes was performed using this method previously reported in [9]. Briefly, the DNA condensation ability of the copolymer was confirmed by electrophoresis. DNA retardation was observed by irradiation with UV light. The sizes and surface charges of FOL-PEG-g-PEI-GAL/DNA complexes were measured at room temperature using an electrophoretic light scattering spectrophotometer at scattering angles of 90 and $20^{\circ}$, respectively. The morphologies of the FOL-PEG-gPEI-GAL/DNA complexes were observed using atomic force microscopy (AFM).

3.8. Cell Line and Cell Culture. HepG2 (human hepatoblastoma) cells were incubated in Dulbecco's modified Eagle medium (DMEM, Gibco BRL, USA) supplemented with $10 \%$ FCS, Streptomycin at $100 \mathrm{mcg} / \mathrm{ml}$, and penicillin at $100 \mathrm{U} / \mathrm{mL}$. The cells were incubated at $37^{\circ} \mathrm{C}$ in a humidified $5 \% \mathrm{CO}_{2}$ atmosphere. Cells were split using Trypsin/EDTA medium prior to reaching confluence.

3.9. Evaluation of Cytotoxicity. In vitro cytotoxicity of the conjugated polymer (FOL-PEG-g-PEI-GAL) was performed by using MTT (3-(4, 5-dimethylthiazol-2-yl)-2, 5-diphenyl tetrazolium bromide) assay. Cells were seeded at initial density of $10^{4}$ cells/well in $200 \mu \mathrm{L}$ of growth medium in 96well plates and incubated for $24 \mathrm{~h}$ to reach $80 \%$ confluences at treatment prior to the addition of filtered FOL-PEG-gPEI-GAL polymer. Growth media were replaced by fresh, serum-free media containing various amounts of polymers or polymer/DNA complexes at various N/P ratios $(5,10,15$, and 18).

Cells were incubated with polymer for 48 and $72 \mathrm{~h}$. Conjugated polymer-untreated cells in media were used as control.

After an additional incubation, $10 \mu \mathrm{L}$ of $5 \mathrm{mg} / \mathrm{ml}$ MTT solution in PBS (1/10 of total volume in a well) was added to each well, and the plate was incubated for $4 \mathrm{~h}$ in a $5 \%$ $\mathrm{CO}_{2}$ humidified atmosphere at $37^{\circ} \mathrm{C}$. One hundred $\mu \mathrm{L}$ of the solubilization solution DMSO was added, and the plates were shaken for $15 \mathrm{~min}$ at $37^{\circ} \mathrm{C}$ by a shaker incubator in order to dissolve the formazan crystals. The optical density of the solution was measured at $570 \mathrm{~nm}$ using an ELISA plate reader with a reference filter of $620 \mathrm{~nm}$. The experiment was repeated three times for each concentration treatment:

$$
\text { Cell Viability }(\%)=\left(\frac{\mathrm{OD}_{570(\text { sample })}}{\mathrm{OD}_{570(\text { control })}}\right) \times 100
$$

where $\mathrm{OD}_{570(\text { sample) }}$ represents measurement from the wells treated with FOL-PEG-g-PEI-GAL copolymer and $\mathrm{OD}_{570 \text { (control) }}$ from the wells treated with only DMEM, $10 \%$ FCS. 


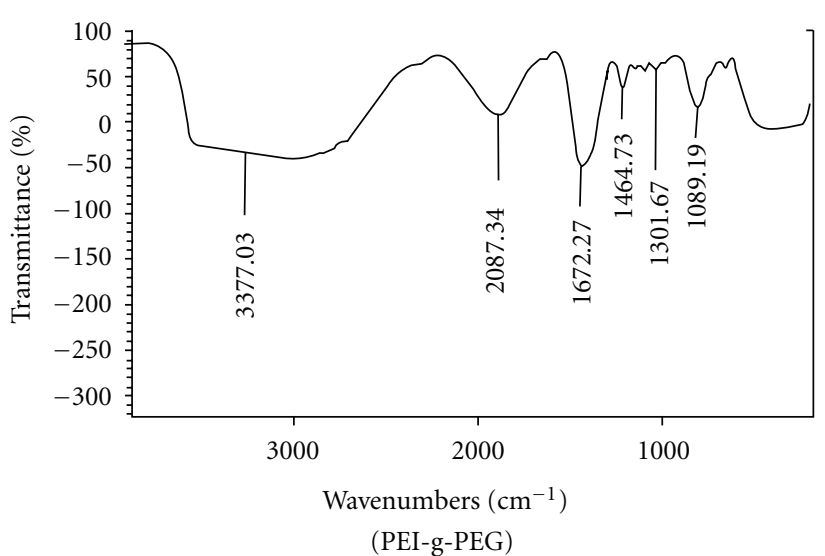

(a)

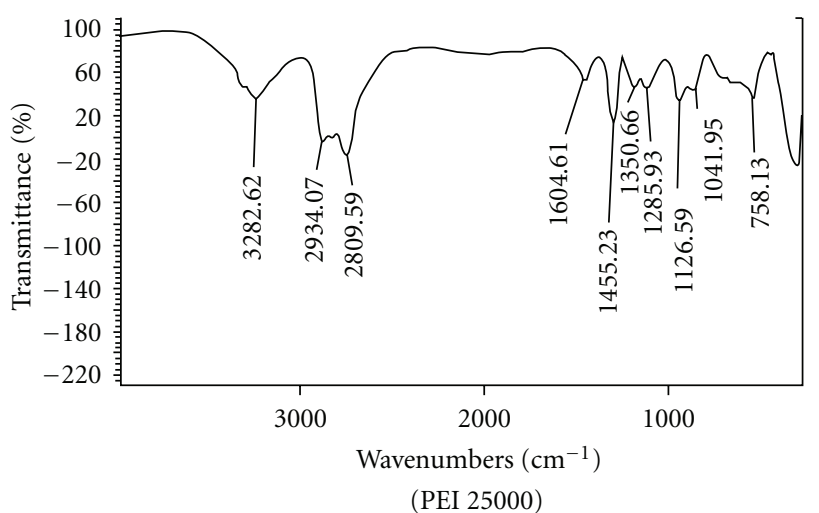

(c)

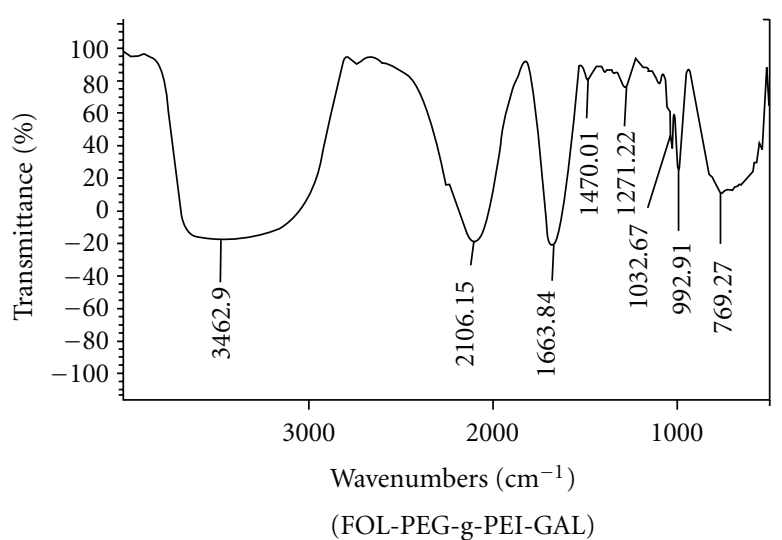

(b)

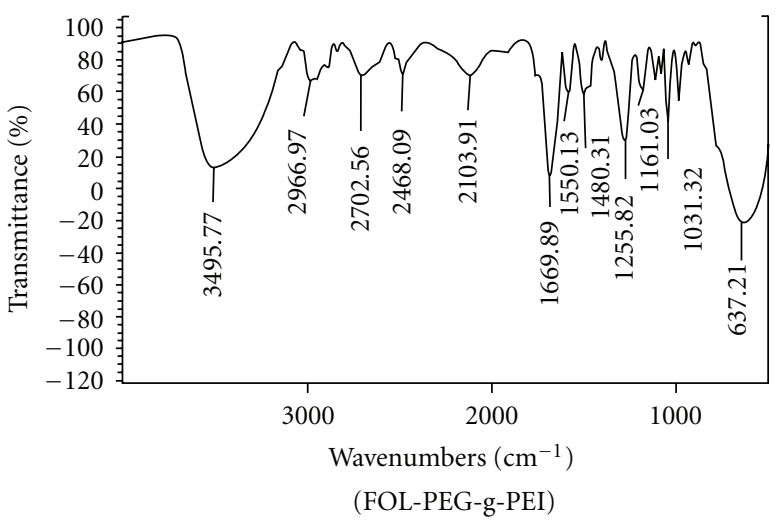

(d)

FIgURe 1: The FTIR spectra of PEI, PEG-g-PEI, FOL-PEG-g-PEI, and FOL-PEG-g-PEI-GAL.

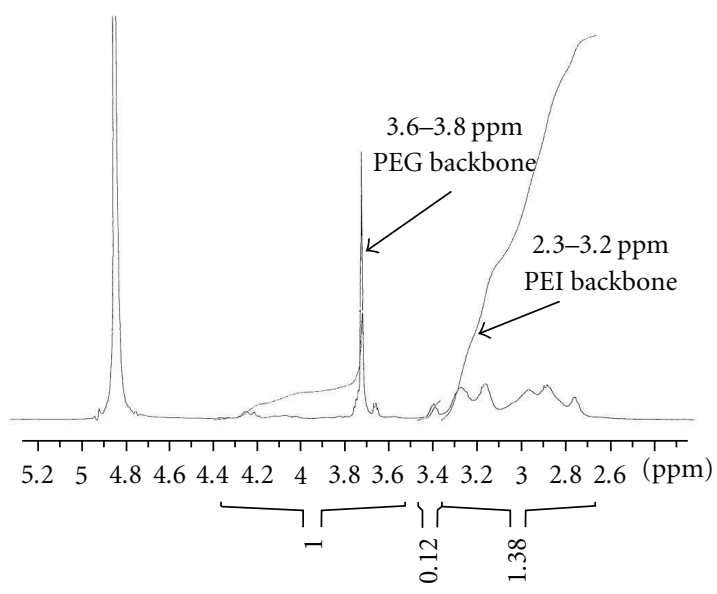

Figure 2: The ${ }^{1} \mathrm{H}-\mathrm{NMR}$ spectrum of PEGylated Polyethylenimine (PEG-g-PEI)/D ${ }_{2} \mathrm{O}$.

3.10. Transfection Efficiency Assay. To measure transfection efficiency, the original cell culture media were replaced with the complexes solution containing the FOl-PEG-g-PEIGAL/DNA nanoparticles and an additional $200 \mu \mathrm{L}$ serumfree DMEM for each well. They were incubated for $6 \mathrm{~h}$ at

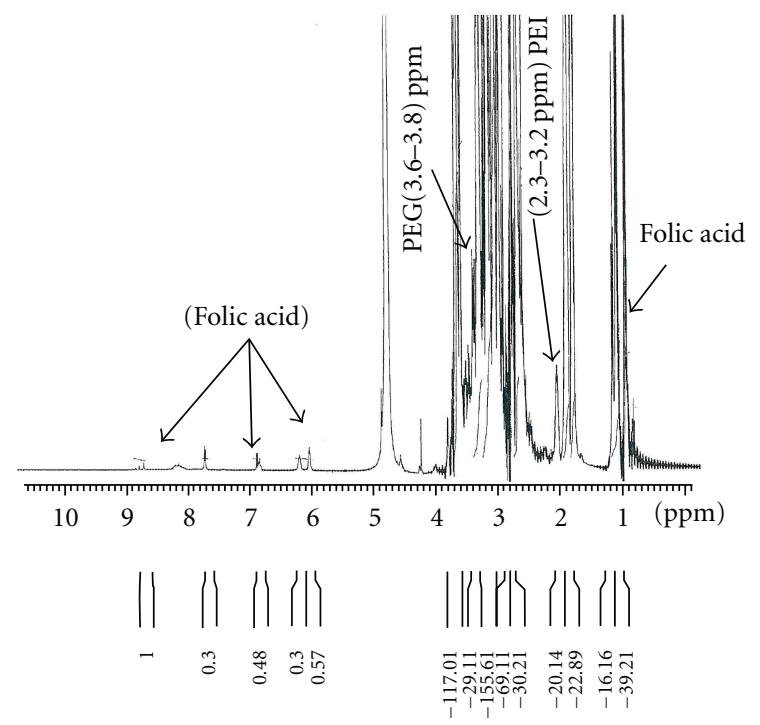

Figure 3: The ${ }^{1} \mathrm{H}-\mathrm{NMR}$ spectrum of FOL-PEG-g-PEI/D ${ }_{2} \mathrm{O}$.

$37^{\circ} \mathrm{C}$. Six hours later, the transfection media were changed with fresh and complete DMEM culture media. The cells were further incubated for $24 \mathrm{~h}$ at $37^{\circ} \mathrm{C}$. 


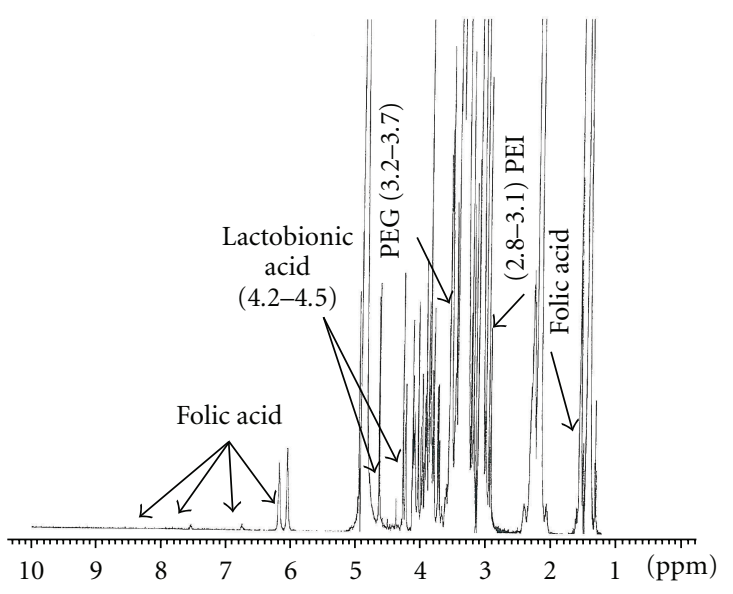

FIgure 4: The ${ }^{1} \mathrm{H}-\mathrm{NMR}$ spectrum of FOL-PEG-g-PEI-GAL/D $\mathrm{D}_{2} \mathrm{O}$.

Transfection efficiency was evaluated by scoring the percentages of cells expressing green fluorescence protein using an FACS Aria TM system flow cytometry. The experiments were performed in triplicates.

3.11. Statistical Analysis. Statistical analysis was performed using Student's $t$-test (Graph Pad Software, San Diego, CA). Data were expressed as mean \pm S.D. Statistical significance was represented by ${ }^{*} P<.05$ and ${ }^{* *} P<.01$.

\section{Results and Discussion}

4.1. Synthesis and Characterization of FOL-PEG-g-PEIGAL Copolymer. The development of gene delivery largely depends upon the therapeutic the development of delivery systems that can introduce therapeutic genes into target cells efficiently and safety $[8,9,11]$.

In the first step, PEG-g-PEI was synthesized to enhance solubility in body and to decrease cytotoxicity in HepG2 cells by decreasing the high cationic surface charge of polyethylenimine.

In order to shield the high surface charge of PEI, a covalent link between bifunctional PEG (NH2-PEG-COOH) and the amine groups of PEI was carried out by activation of carboxylic acid group [8,9]. We used the bifunctional PEG which has the amine group at one side and also, the carboxylic acid group at the other side. Decreasing of the high cationic surface charge of PEI could seem to diminish the cytotoxicity of PEI. Furthermore, PEGylation facilitates the formation of polyplexes with diminished aggregation and possibly decreased opsonization with serum proteins in bloodstream $[6,8,9]$.

In the next, FOL-PEG-g-PEI and FOL-PEG-g-PEI-GAL were prepared.

4.2. Characterization of Conjugated Copolymers. The FTIR spectrum of polyethylenimine, PEG-g-PEI, FOL-PEG-g-PEI, and FOL-PEG-g-PEI-GAL copolymers were illustrated in Figure 1 .
The FTIR spectrum showed that polyethylene glycol was grafted on the PEI chains.

Upon grafting reaction, strong absorption around $1667 \mathrm{~cm}^{-1}$ attributed to the amide linkage appeared in the all of spectra of graft copolymers (b, c, and d) (compared with Figure 1(a)). In addition, the graft copolymers showed strong and broad absorption of amines around $3450 \mathrm{~cm}^{-1}$ $(\mathrm{N}-\mathrm{H})$ because of the strong group of $\mathrm{N}-\mathrm{H}$ bound.

The ${ }^{1} \mathrm{H}-\mathrm{NMR}$ spectra of pegylated Polyethylenimine, FOL-PEG-g-PEI, FOL-PEG-g-PEI-GAL solution in $\mathrm{D}_{2} \mathrm{O}$ were presented in Figures 2-4. The peaks at 2.7-3.3 ppm were attributed to the ethylenimine $\left(-\mathrm{N}-\mathrm{CH}_{2} \mathrm{CH}_{2}\right)$ groups proton in polyethylenimine in ${ }^{1} \mathrm{H}-\mathrm{NMR}$ of PEI [5].

In ${ }^{1} \mathrm{H}-\mathrm{NMR}$ of PEG-PEI (Figure 2), the peaks at (3.33.8) ppm could refer to the ethylene glycol $\left(-\mathrm{O}-\mathrm{CH}_{2} \mathrm{CH}_{2}\right)$ group's proton in PEG. These peaks proved that the bifunctional polyethylene glycol has reacted with the amine groups of PEI. The intense band at $4.8 \mathrm{ppm}$ was due to $\mathrm{D}_{2} \mathrm{O}$ as a solvent. The ratios of PEG and PEI in copolymers were determined by ${ }^{1} \mathrm{H}-\mathrm{NMR}$ spectra using AUC obtained from the number of $\left(-\mathrm{CH}_{2} \mathrm{CH}_{2}-\mathrm{O}-\right)$ protons of PEG to the number of $\left(-\mathrm{CH}_{2} \mathrm{CH}_{2}-\mathrm{NH}-\right)$ protons of PEI. That was calculated as 0.75 (ratio of PEG/PEI).

According to Figure 3 (FOL-PEG-g-PEI copolymer). the peaks at $7.6 \mathrm{ppm}, 8.17 \mathrm{ppm}$, and $8.2 \mathrm{ppm}$ were attributed to aromatic hydrogen's of folic acid that confirmed the linkage of folic acid to PEG-g-PEI. The other peaks related to PEI and PEG are also observable at field area of spectrum in 2.6$3.3 \mathrm{ppm}$ and 3.2-3.8 ppm, respectively.

The peaks at $1.1 \mathrm{ppm}$ could be referred to the aliphatic protons at side chain of folic acid. It seems that the terminal $\gamma$-carboxylic acid group of folate was activated by EDC/NHS and conjugated to the terminal amine groups of a heterofunctional PEG derivate (COOH-PEG-NH known that the folate has two $\alpha$ - and $\gamma$-carboxylic acids; however $\gamma$-carboxylic acid is more selectively activated due to its higher activity $[6,7]$. From the relative intensity ratio of proton peaks of folic acid corresponding to the proton peaks of PEG-g-PEI, it was estimated that the ratio between folic acid and graft copolymer (PEG-g-PEI) was $1: 5.72$.

The ${ }^{1} \mathrm{H}-\mathrm{NMR}$ of FOL-PEG-g-PEI-GAL copolymer is illustrated in Figure 4. The peaks at 2.6-3.2 ppm were attributed to the ethylenimine units in PEI. The peaks at 3.3-3.8 ppm were attributed to the ethylene glycol units in hetero-functional PEG. Finally, peaks at 4.2 and $4.5 \mathrm{ppm}$ in ${ }^{1} \mathrm{H}$-NMR of FOL-PEG-g-PEI-GAL were related to Lactobionic acid moiety that confirmed the linkage of lactobionic acid in last stage. The chemical composition of the galactose group in FOl-PEG-g-PEI-GAL was determined to be 14.2 mol\% by assigning the protons of ethylenimine in PEI and the proton of the 1-carbon in galactose (Figures 4 and 5).

4.3. Zeta Potential Measurement. Zeta potential was correlated to the cytotoxicity of the copolymers. When the surface charge of copolymer is high, this copolymer can be cytotoxic in many cell lines. 


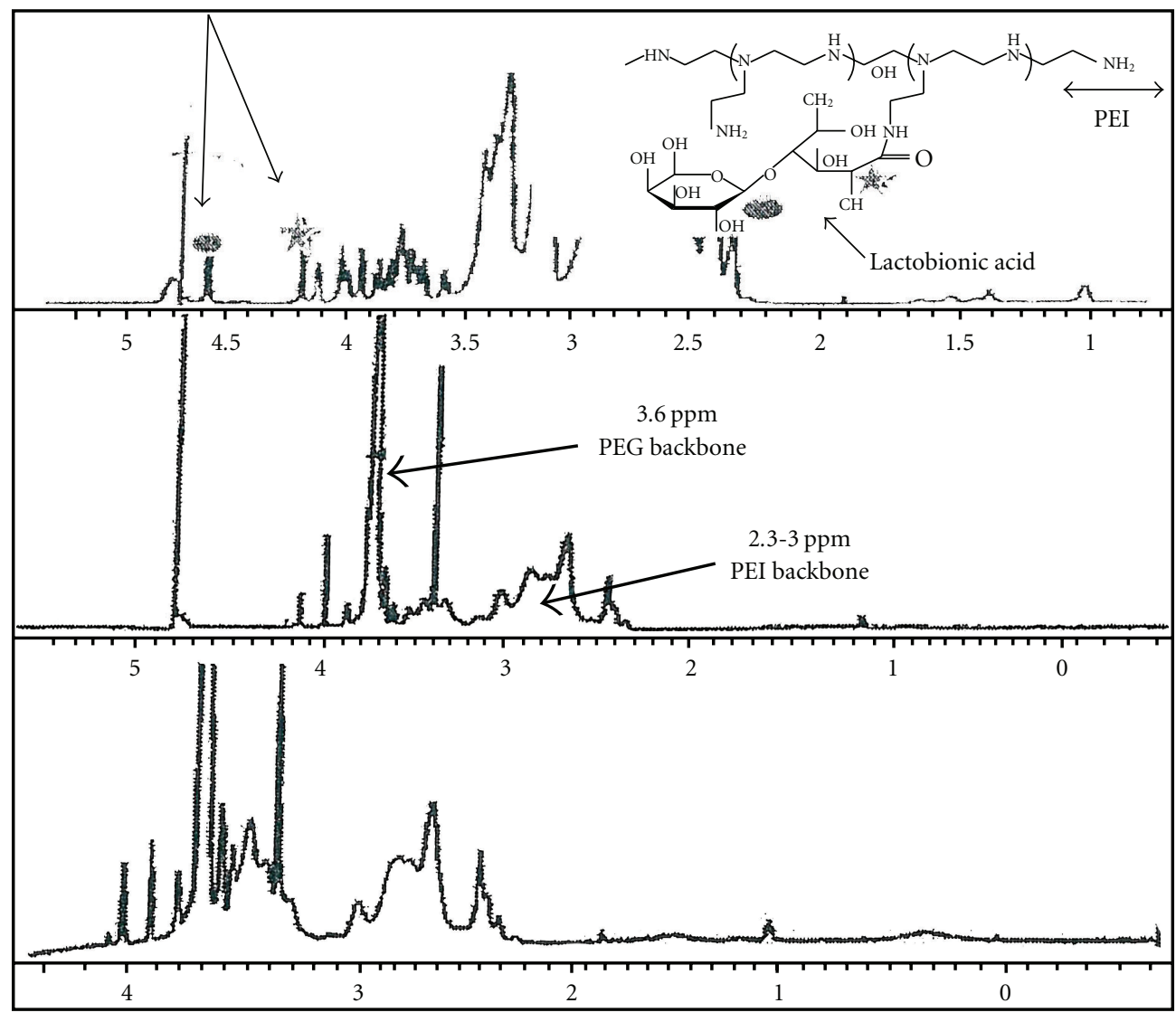

(ppm)

FIgure 5: The ${ }^{1} \mathrm{H}-\mathrm{NMR}$ spectrum of attraction between Lactobionic acid with PEGylated Polyethylenimine.

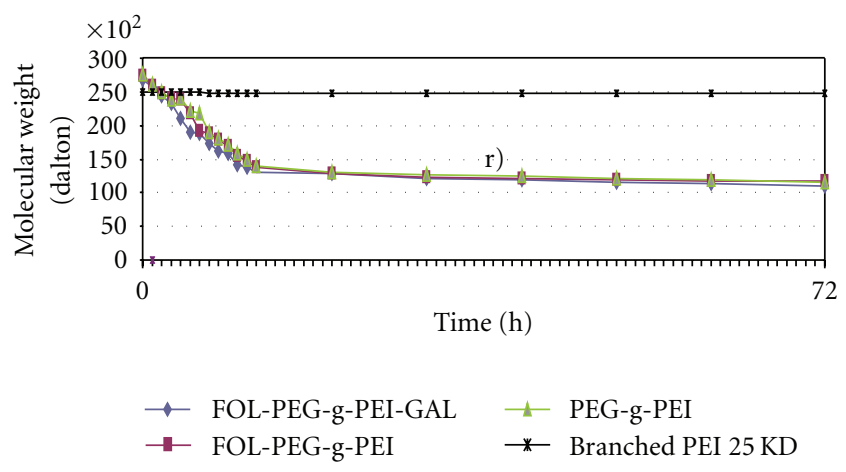

Figure 6: Degradation of synthesized copolymers in $0.1 \mathrm{M}$ PBS at $37^{\circ} \mathrm{C}$ and $100 \mathrm{rpm}$. Determination of molecular weight was measured by GPC instrument. The half-lives were longer than result of Duan et al. [5].

As presented in Table 1, the zeta potential of PEI was particularly high, indicating the high cationic surface charge and its cytotoxicity. Zeta potential decreased after grafting hydrophilic PEG, ascribing to the shielding effect of PEG. FOL-PEG-g-PEI-GAL showed the lowest zeta potential indicating a considerable reduction in the number of positive surface charge and its cytotoxicity.

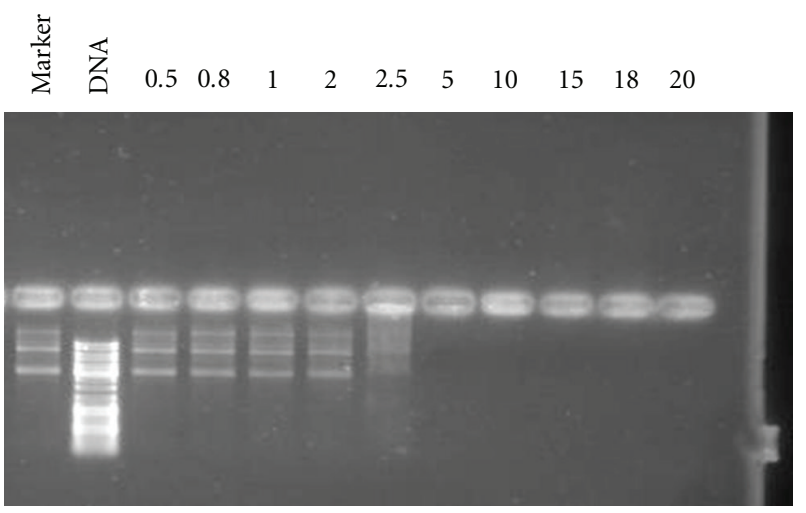

Figure 7: Agarose gel electrophoresis of FOL-PEG-g-PEIGAL/DNA complexes at various N/P ratios.

The zeta potential positivity of the copolymers had the following order:

PEI $>$ PEG-g-PEI > FOL-PEG-g-PEI > FOL-PEG-g-PEI-GAL.

As expected, the zeta potential of PEI was higher than the final obtained copolymer because of the PEGylation on PEI and also targeting moiety. 


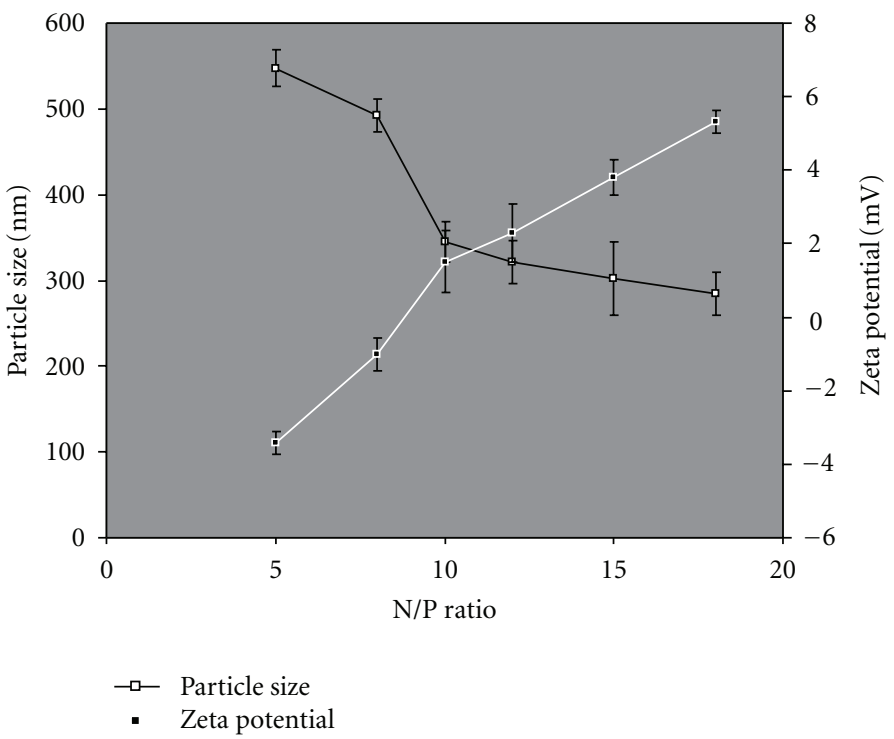

(a)

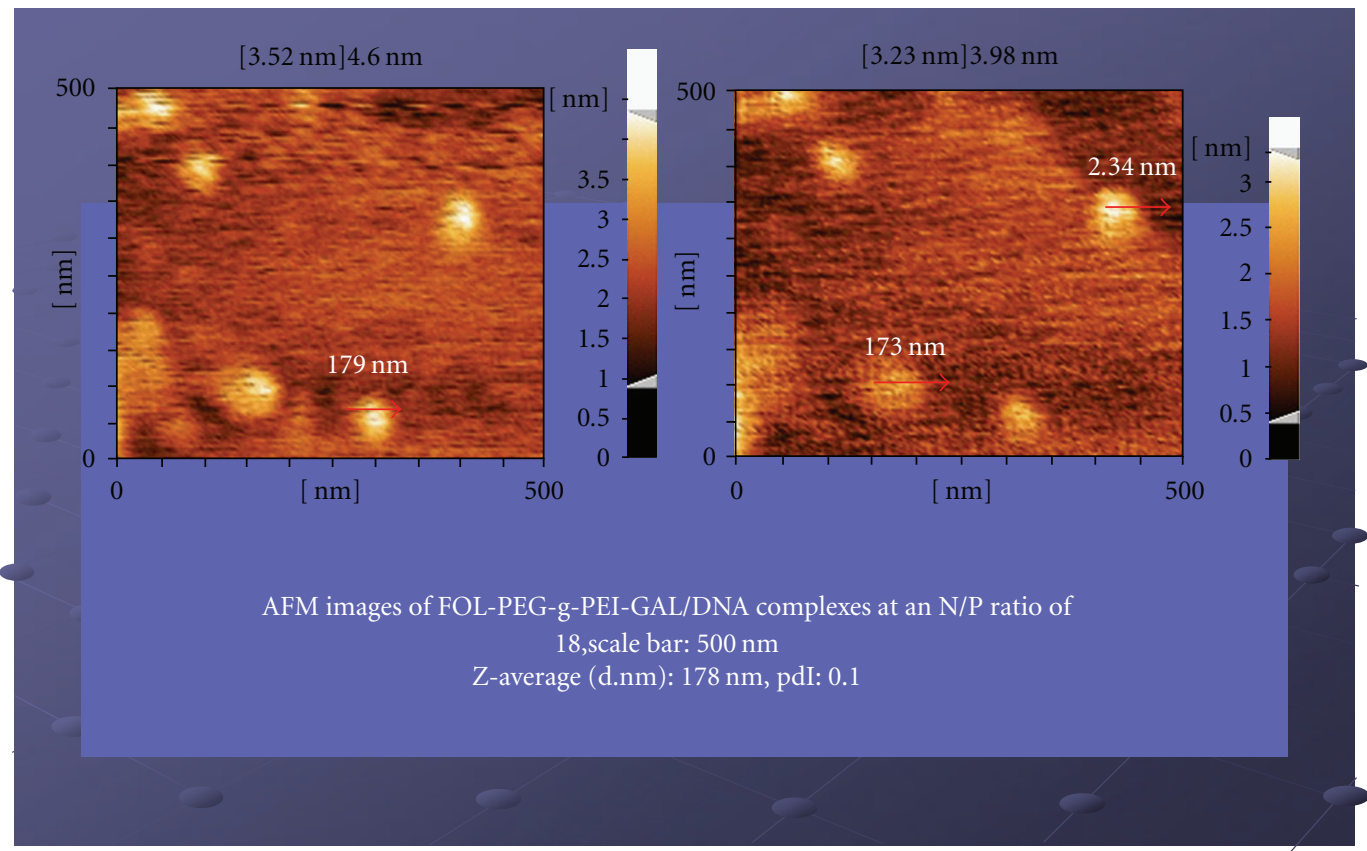

(b)

Figure 8: (a) Particle sizes and charges of copolymer/DNA complexes at various N/P ratios ( $n=3$, error bars represent standard deviation). (b) AFM images of FOL-PEG-g-PEI-GAL/DNA complexes at an N/P ratio of 18, scale bar: $500 \mathrm{~nm}$.

Therefore, the stability and biodegradability of this new copolymer was exactly increased in blood circulation due to the decreasing of high cationic surface charge of FOL-PEGg-PEI-GAL copolymer.

Also, this synthesized copolymer needs the lowest positive charge to condense the negative charge DNA via electrostatic attraction. The low positivity of the surface charge in FOL-PEG-g-PEI-GAL could condense plasmid DNA well in N/P ratio 5 and higher N/P ratio as shown in Figure 7. The ratio of amine groups of polyethylenimine to phosphate groups of DNA is called N/P ratio. N/P ratio is very important factor in gene delivery, and it correlates the particle sizes, zeta potential, and transfection efficiency of copolymer/DNA complexes.

Although the size and configuration of the new copolymer are also important factors in their reaction with the cellular receptors, the folic acid and galactose (lactobionic acid) are usually very compact and show less strict hindrance.

Copolymers revealed unimodal molecular weight distribution in GPC chromatograms (data not shown), indicating no PEG prepolymer or unreacted PEI or other unreacted substrate in the all copolymers. 


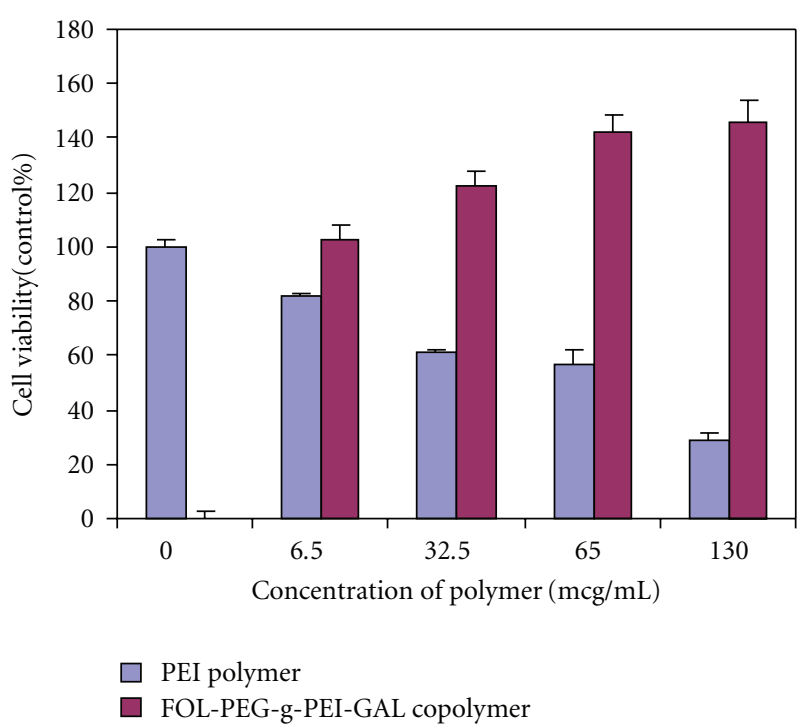

(a)

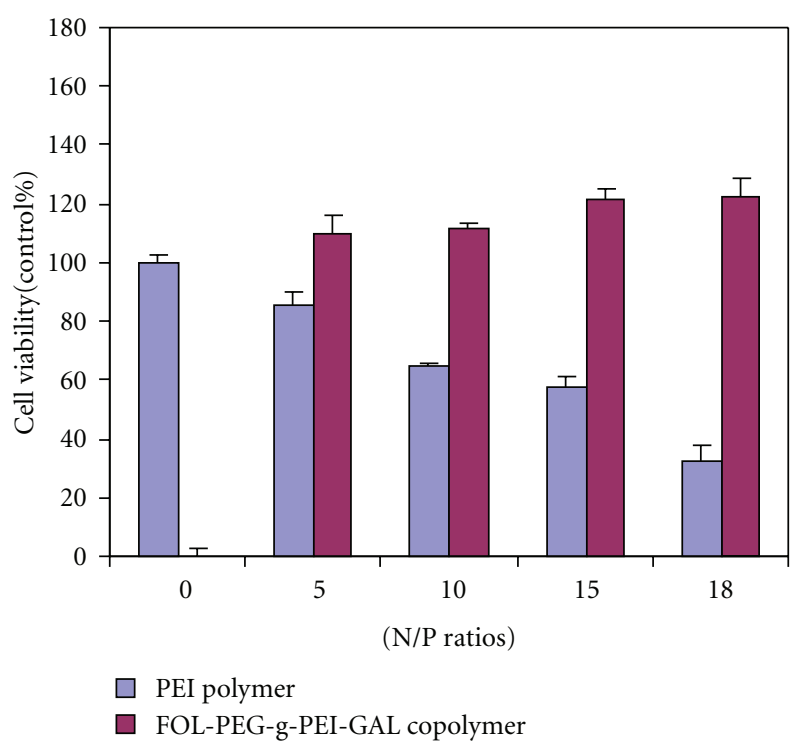

(b)

FIgUre 9: (a) Cytotoxicity of the "PEI" Polymer and "FOL-PEG-g-PEI-GAL" copolymer at various concentrations in HepG2 cell line ( $n=3$, error bars represent standard deviation). (b) Cytotoxicity induced after adding of the Polymer/DNA complexes in HepG2 cell line at various $\mathrm{N} / \mathrm{P}$ ratios $(n=3$, error bars represent standard deviation).

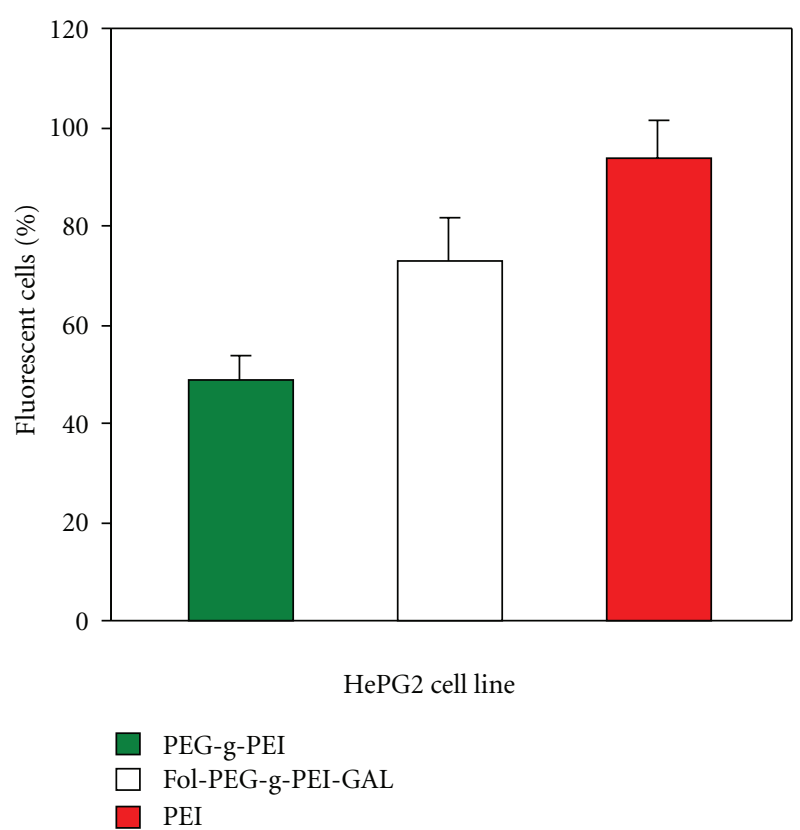

Figure 10: Transfection efficiency of PEG-g-PEI/pEGFP, FOL-PEGg-PEI-GAL/pEGFP, and PEI/pEGFP complexes by FACS analysis in HepG2 cells at N/P ratio $=18$. Transfection was performed at a dose of $1 \mathrm{mg}$ of DNA (mean $\pm \mathrm{SD}, n=3$ ). $y$-axis shows the \%fluorescent cells.

4.4. Degradation of Copolymers. In vivo degradation of polymer is very important for safe and efficient gene delivery [6].
The appropriate degradation of polymer enables reduction of cytotoxicity due to reducing the number of positive charge [11-13].

The commonly used polyethylenimine $(25 \mathrm{~K})$ is toxic in many cell lines because the PEI does not degrade in serum media $[8,9,11,12]$. PEI accumulates in body, and then penetrates to many cell lines [11]. In fact, the potential cytotoxicity of PEI could be referred to its accumulation in body and it is one the most important disadvantages of this cationic polymer. With grafting of PEG chains with polyethyleneimine, the amide linkages are susceptible to hydrolysis at physiological conditions. PEG is known to help increase the hydrophilic properties of PEI because of the hydrophilic groups of PEG [14]. The advantage of conjugation formation could be increasing the biodegradability in blood circulation, and PEGylation will reduce the high cationic surface charge of PEI $[6,8,9]$. In general, PEG facilitates the formation of polyp lexes with improved solubility, lower surface charge, diminished aggregation, lower cytotoxicity, and possibly decreased opsonization with serum proteins in bloodstream $[8,11]$.

Degradation of copolymers was shown in Figure 6, indicating that the synthesized conjugated copolymers degraded rapidly at $37^{\circ} \mathrm{C}$ in PBS especially at early times $[6,7]$

Molecular weights of the synthesized copolymers were maintained relatively constant at about $11000 \mathrm{Da}$ after $72 \mathrm{~h}$ but PEI was not biodegradable in this condition as it shown in Figure 6.

4.5. Preparation and Characterization of FOL-PEG-g-PEIGAL/DNA Nanoparticles. N/P ratio is very important in 
TAble 1: The zeta potential and molecular weight of PEI, PEG-g-PEI copolymer, FOL-PEG-g-PEI copolymer, and FOL-PEG-g-PEI-GAL copolymer.

\begin{tabular}{lccc}
\hline Polymer & Zeta potential of copolymer $(\mathrm{mV})^{\mathrm{a}}$ & ${\text { Molecular weight of copolymer }(\mathrm{KD})^{\mathrm{b}}}^{\mathrm{a}}$ & Poly dispersity b $^{\text {Polyethylenimine }}$ \\
\hline PEG-g-PEI & $+41.1 \pm 1.4$ & 25.0 & 1.2 \\
FOL-PEG-g-PEI & $+32.7 \pm 3.2$ & 26.9 & 1.3 \\
FOL-PEG-g-PEI-GAL & $+21.7 \pm 1.9$ & 27.3 & 1.3 \\
\hline
\end{tabular}

${ }^{\mathrm{a}}$ Determined by ${ }^{1} \mathrm{H}-\mathrm{NMR}$

${ }^{\mathrm{b}}$ Determined by GPC.

gene delivery. The condensation capability of FOL-PEG-gPEI-GAL copolymer with DNA was evaluated using agarose gel electrophoresis.

As shown in Figure 7, the migration of DNA was completely retarded when the N/P ratio reached approximately 5.

Also, particle size is a particularly important factor that influences the access and passage of complexes through the targeted site [11-13]. As shown in Figure 8(a), all complexes were less than $300 \mathrm{~nm}$, and particle sizes tended to decrease with an increase in the N/P ratio; it is thought that the hydrophilic groups of the FOL-PEG and GAL residue prevented aggregation of the complexes.

A positive surface charge is necessary for binding to anionic cell surfaces, which in turn facilitates uptake into the cells [13-16]. As shown in Figure 8(a), the zeta potentials of FOL-PEG-g-PEI-GAL/DNA complexes rapidly increased to positive values with increasing N/P ratios.

Together, these results suggested that FOL-PEG-g-PEIGAL copolymer could efficiently transfer DNA to cells after complexation, and the proper particle size $(284 \mathrm{~nm})$ and proper zeta potential $(+5.42 \mathrm{mV})$ of FOL-PEG-g-PEIGAL/DNA complex were prepared at N/P $=18$.

Figure 8(b) AFM shows representative morphologies of FOL-PEG-g-PEI-GAL/DNA complexes. The results suggested well-formed spherical shapes with compact structure.

4.6. Cytotoxicity of Copolymer. To investigate the cytotoxicity of the FOL-PEG-g-PEI-GAL copolymer, cell viability was assayed at various concentrations of the copolymer using human hepatoblastoma cell line (HepG2).

Figure 9(a)shows cell viability decreased drastically with increasing concentration of PEI $25 \mathrm{~K}$ whereas the FOLPEG-g-PEI-GAL did not exhibit cytotoxicity even at high concentration $(130 \mu \mathrm{g} / \mathrm{ml})$.

In the texts, PEI is highly toxic in many cell lines at $130 \mu \mathrm{g} / \mathrm{mL}$ [7-16]. So, we assayed this novel copolymer to this concentration, and the results show no cytotoxicity in HepG2.The cell viabilities of FOL-PEG-g-PEI-GAL/DNA and PEI/DNA complexes were also assayed at various N/P ratios Figure 9(b). These N/P ratios were calculated related to the concentrations. Among the cell line, FOL-PEG-g-PEIGAL/DNA complexes remarkably showed no cytotoxicity than PEI $25 \mathrm{~K}$.

The cytotoxicity of cationic polymers is likely due to polymer aggregation on cell surfaces, impairing important membrane function. Also, cationic polymers may interfere with critical intracellular processes: in particular, the primary amine was reported to disrupt PKC function through disturbance of protein kinase activity $[14,16,17]$. PEG is known to help reduce the cytotoxicity of PEI amino groups [14-17]. Therefore, it is reasonable to assume that FOLPEG-g-PEI-GAL was less cytotoxic than PEI $25 \mathrm{~K}$ due to the properties of hydrophilic groups of PEG.

In fact, this novel bioactive and biocompatible polymer has no cytotoxicity in cultured HepG2, and it has potential to enter to human hepatoblastoma cells (HepG2) specifically.

4.7. Transfection Efficiency Assays. The transfection efficiency was quantified by flow cytometry assay. Our results showed that the ratio of EGFP-Positive cells is $93 \%, 73 \%$, and $49 \%$ when HepG2 cells were transfected with PEI, FOLPEG-g-PEI-GAL, and PEG-g-PEI copolymer/pAAV-EGFP complexes, respectively (Figure 10).

Based on the results of flow cytometry, it was also found that when the N/P ratio was 18, the FOL-PEG-g-PEIGAL/DNA possessed the highest transfection efficiency in HepG2 than the other synthesized copolymer.

\section{Conclusion}

In this study, the FOL-PEG-g-PEI-GAL copolymer as a novel biocompatible polymer was synthesized and characterized using ${ }^{1} \mathrm{H}-\mathrm{NMR}$ and FTIR for the first time to our knowledge.

The obtained copolymer has positive surface charge about $+17.3 \mathrm{mV}$, and it has less zeta potential than PEI. The FOL-PEG-g-PEI-GAL nanoparticle with the $284 \mathrm{~nm}$ has an enhanced ability to form complexes with DNA at N/P ratio 18 and has physicochemical properties suitable for a gene delivery system. This copolymer had no cytotoxicity in HepG2 cell line when compared to PEI $25 \mathrm{~K}$.

Moreover, the transfection efficacy of this conjugated copolymer in HepG2 cell line was significantly enhanced compared to PEI. The results suggest that the targeted copolymer might be a promising candidate for gene delivery to cancer liver cells with high transfection efficiency, low cytotoxicity. The studies on their in vivo toxicity and gene delivery efficacy should be further conducted in different animal models. 


\section{Acknowledgments}

This paper was supported by Ave Sina research center, Tehran, Iran. The authors are grateful for the help of Dr. M. Jeddi Tehrani, Dr. H. Rabbani, and the broad of directors through out this study.

\section{References}

[1] C. Woffendin, U. Ranga, Z.-Y. Yang, L. Xu, and G. J. Nabel, "Expression of a protective gene prolongs survival of $\mathrm{T}$ cells in human immunodeficiency virus-infected patients," Proceedings of the National Academy of Sciences of the United States of America, vol. 93, no. 7, pp. 2889-2894, 1996.

[2] S. M. Hammond, A. A. Caudy, and G. J. Hannon, "Posttranscriptional gene silencing by double-stranded RNA," Nature Reviews Genetics, vol. 2, no. 2, pp. 110-119, 2001.

[3] G. J. Nabel, "Genetic cellular and immune approaches to disease therapy: past and future," Nature Medicine, vol. 10, no. 2, pp. 135-141, 2004.

[4] A. M. M. Sadeghi, M. Amini, M. R. Avadi, F. Siedi, M. RafieeTehrani, and H. E. Junginger, "Synthesis, characterization, and antibacterial effects of trimethylated and triethylated 6NH2-6-deoxy chitosan," Journal of Bioactive and Compatible Polymers, vol. 23, no. 3, pp. 262-275, 2008.

[5] Y. Duan, J. Zheng, S. Han et al., "A tumor targeted gene vector modified with G250 monoclonal antibody for gene therapy," Journal of Controlled Release, vol. 127, no. 2, pp. 173-179, 2008.

[6] M. R. Park, K. O. Han, I. K. Han, et al., "Degradable polyethylenimine-alt-poly(ethylene glycol) copolymers as novel gene carriers," Journal of Controlled Release, vol. 105, no. 3, pp. 367-380, 2005.

[7] S. H. Kim, J. H. Jeong, C. K. Cho, S. W. Kim, and T. G. Park, "Target-specific gene silencing by siRNA plasmid DNA complexed with folate-modified poly(ethylenimine)," Journal of Controlled Release, vol. 104, no. 1, pp. 223-232, 2005.

[8] E.-M. Kim, H.-J. Jeong, I.-K. Park et al., "Asialoglycoprotein receptor targeted gene delivery using galactosylated polyethylenimine-graft-poly(ethylene glycol): in vitro and in vivo studies," Journal of Controlled Release, vol. 108, no. 2-3, pp. 557-567, 2005.

[9] H.-L. Jiang, J.-T. Kwon, E.-M. Kim et al., "Galactosylated poly(ethylene glycol)-chitosan-graft-polyethylenimine as a gene carrier for hepatocyte-targeting," Journal of Controlled Release, vol. 131, no. 2, pp. 150-157, 2008.

[10] S. Xu, M. Chen, Y. Yao et al., "Novel poly(ethylene imine) biscarbamate conjugate as an efficient and nontoxic gene delivery system," Journal of Controlled Release, vol. 130, no. 1, pp. 64-68, 2008.

[11] C.-H. Ahn, S. Y. Chae, Y. H. Bae, and S. W. Kim, "Biodegradable poly(ethylenimine) for plasmid DNA delivery," Journal of Controlled Release, vol. 80, no. 1-3, pp. 273-282, 2002.

[12] S. Kommareddy and M. Amiji, "Preparation and evaluation of thiol-modified gelatin nanoparticles for intracellular DNA delivery in response to glutathione," Bioconjugate Chemistry, vol. 16, no. 6, pp. 1423-1432, 2005.

[13] G. Kaul and M. Amiji, "Cellular interactions and in vitro DNA transfection studies with poly(ethylene glycol)-modified gelatin nanoparticles," Journal of Pharmaceutical Sciences, vol. 94, no. 1, pp. 184-198, 2005.

[14] S. Davaran, Y. Omidi, R. R. Mohammad et al., "Preparation and in vitro evaluation of linear and star-branched PLGA nanoparticles for insulin delivery," Journal of Bioactive and Compatible Polymers, vol. 23, no. 2, pp. 115-131, 2008.

[15] H.-L. Jiang, Y.-K. Kim, R. Arote et al., "Chitosan-graftpolyethylenimine as a gene carrier," Journal of Controlled Release, vol. 117, no. 2, pp. 273-280, 2007.

[16] K. Kunath, A. Von Harpe, D. Fischer et al., "Low-molecularweight polyethylenimine as a non-viral vector for DNA delivery: comparison of physicochemical properties, transfection efficiency and in vivo distribution with high-molecular-weight polyethylenimine," Journal of Controlled Release, vol. 89, no. 1, pp. 113-125, 2003.

[17] E. Lih, K. J. Yoon, W. B. Jin, and D. P. Ki, "An in situ gelforming heparin-conjugated PLGA-PEG-PLGA copolymer," Journal of Bioactive and Compatible Polymers, vol. 23, no. 5, pp. 444-457, 2008. 

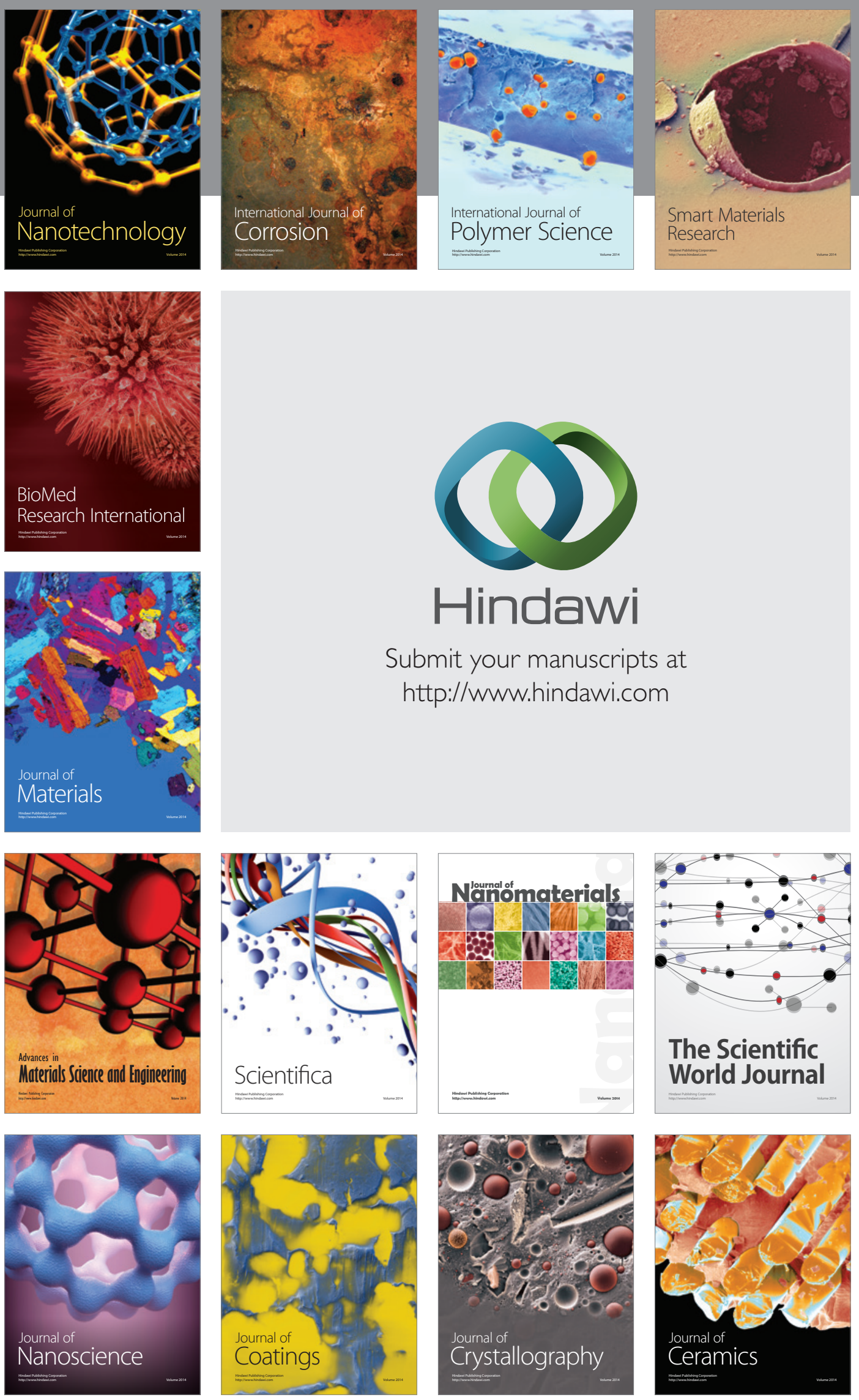

The Scientific World Journal

Submit your manuscripts at

http://www.hindawi.com

\section{World Journal}

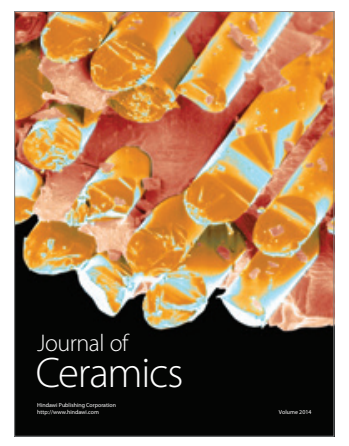

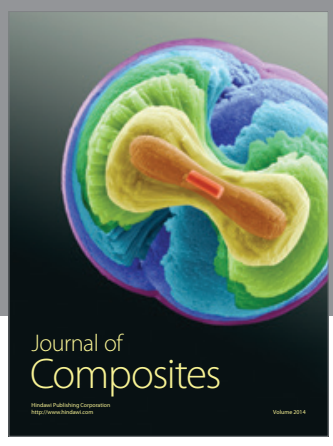
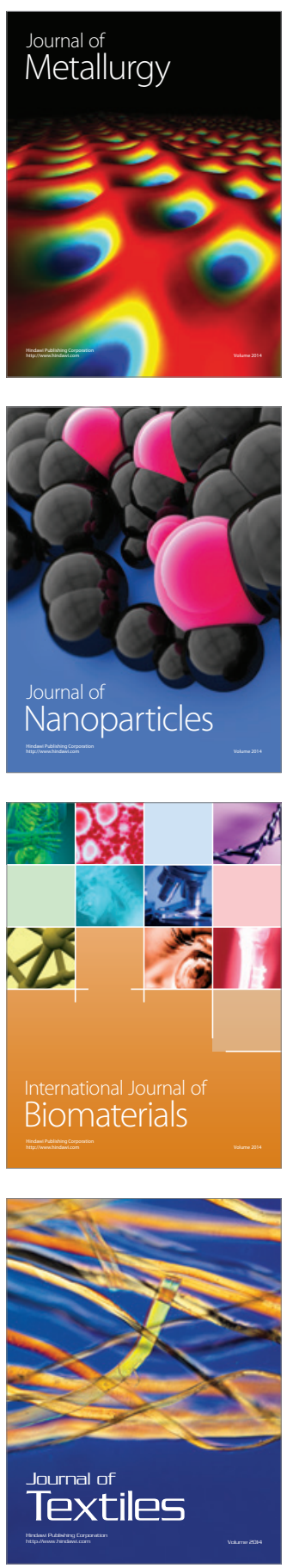